\title{
Factors Influencing Age at First Birth of Bangladeshi Women- A Multivariate Approach
}

\author{
Ahbab Mohammad Fazle Rabbi ${ }^{1}$, M.H.M. Imrul Kabir ${ }^{2, *}$ \\ ${ }^{1}$ Department of Applied Science, Bangladesh University of Textiles, Dhaka, Bangladesh \\ ${ }^{2}$ Department of Applied Statistics, East-West University, Dhaka, Bangladesh \\ *Corresponding author: ikabirdu@gmail.com
}

Received July 09, 2013; Revised August 03, 2013; Accepted August 06, 2013

\begin{abstract}
Age at first birth has direct effect on fertility; early initiation of childbearing lengthens the reproductive period and subsequently increases fertility level of a country. Study of age at first birth enable researchers to forecast about subsequent fertility behavior and policy implications, especially in case of developing country like Bangladesh; where third stage of demographic transition begun as a result of continuous assessment. Multivariate techniques have been applied using BDHS-2007 data to obtain significant determinants of age at first birth of Bangladeshi women. Five factors were revealed from factor analysis where consciousness of parents and fecundity factor explain the age at first birth most. Linear discriminant analysis revealed that $70.9 \%$ of original grouped cases were correctly classified according to the obtained factors where, sensitivity of discriminant function was $71.9 \%$ and the specificity was $65.1 \%$. Findings suggest that; there is a complex structure to the decision-making for first parity along with couple's awareness about population boost, fecundity, couple's educational level and, mother's participation on labor force.
\end{abstract}

Keywords: factor analysis, discriminant analysis, age at first birth, Bangladesh

Cite This Article: Ahbab Mohammad Fazle Rabbi, and M.H.M. Imrul Kabir, "Factors Influencing Age at First Birth of Bangladeshi Women- A Multivariate Approach.” American Journal of Public Health Research 1, no. 7 (2013): 191-195. doi: 10.12691/ajphr-1-7-8.

\section{Introduction}

Both researchers and the public have huge interest on the 'average' age of women when they have a child, especially their first. The first birth is a transition marks to a woman into motherhood. It plays a significant role in the future life of each individual woman and possesses a direct relationship with fertility. The age at which child bearing begins influences the number of children a woman bears throughout her reproductive period, in other words, the whole reproductive life span. Thus, the mother's age at first birth influences the total number of births that she might have in her life, which impacts the size, composition, and future growth of the population [1]. Early childbearing may adversely affect the health of mother and infant, economic welfare of the family [2]. Early pregnancies are significantly associated with bad prenatal health care and vaccination behavior, lower birth weights, earlier weaning, and, especially during the second year of life, higher mortality [3,4,5]. A summarized results from data of 36 Demographic and Health Surveys (DHS) and World Fertility Surveys (WFS) showed that the average relative risk of death before age five is about $46 \%$ higher for children born to mothers under 18 , and $13 \%$ higher for those born to mothers aged 18-19, compared with children of mothers aged 20-34 [6].
A growing number of studies suggest that family wellbeing is conditioned by how soon childbearing is begun and how rapidly it proceeds. Expansion of contraceptive use, increase in woman's education and labor force participation have been argued as the reasons of delayed first parity also a reason of fertility decline in previous studies $[7,8,9]$. Women who had first births early tend to have a higher number of births than those whose first birth occurs late, regardless of birth cohort [10]. Family planning also should be taken into account in this question, though for Iran, the modest effect of the family planning program suggests that non-program factors such as woman's education which show sizable impact should be credited for the fertility decline [11].

Few other studies also suggest the effect of education, wealth, race, living place (urban/rural), on age at first birth. The effect of education on age at first birth is a duplex one. The composite effect of education on young women's entry into motherhood has been studied [12]. In line with previous research, the findings of this study suggest that school enrolment delays motherhood, but having finished education there is a catching-up effect, as women who have completed at higher levels have their first child sooner than women who have completed at lower levels. The effect of employment was also observed in previous studies [13]. The findings support the proposition that different determinants come into prominence at different parities, including education. 
Examining the reproductive behavior of Tanzanian women, it has been obtained that the education of a woman, place of residence, and religion play the greatest roles in influencing age at first birth in Tanzania [14]. This study furthermore found that one percent of all first live births resulted from premarital conceptions. In case of socio-economical status and race, previous studies revealed that, economic conditions are important macro level forces driving the transition to parenthood [15]. The results indicate that economic conditions are significant predictors of both outcomes, with economic conditions for females having effects different from those for males. Although a few social determinants do have a direct effect on age at first birth (such as race, religion, and smoking at young ages), most determinants affect age at first birth through education [16].

In Bangladesh, the median age at first birth is about 18 years across all age cohorts, except for women age 20-24 years, whose median age at first birth is 19 years, indicating a slight increase in the age at first birth in recent years. A comparison of data from the 2004 and 2007 BDHS surveys shows a slight increase in the median age at first birth for women in all age groups [17]. Like others developing countries, in Bangladesh, socio-economical pattern also plays vital role on fertility. Among socioeconomic and cultural determinants, family pressure explained the most significant variance in previous studies [18]. It is really difficult to reduce fertility in complex socio-cultural settings in rural Bangladesh. Fertility pattern have been analyzed in recent studies to reveal the most influential fertility inhibiting and enhancing factors for married adolescents in Bangladesh [19]. Among all proximate covariates highest level of education is speculated as the most influential fertility inhibiting factor for adolescents.

In most of the previous studies, the researchers tried to identify significant determinant or sometimes differentials of fertility by examining determinants of age at first birth. In current study, we tried to explore the underlying factors that determine the respondent's age at first birth instead of usual regression analysis. The benefit is vast- no more multicollinearity problem or heteroscedasticity problem; which are common in case of any study involving socioeconomical variables. From a set of possible explanatory variable we are exploring the possible underlying factors which are explaining age at first birth of Bangladeshi women most plausibly.

\section{Data and Analysis Procedure}

The data for this study is obtained from Bangladesh Demographic and Health Survey (BDHS) 2007 which is a nationally representative survey was conducted under the authority of the National Institute for Population, Research and Training (NIPORT) of the Ministry of Health and Welfare, Bangladesh and funded by USAID. BDHS-2007 is a nationally representative sample survey designed to provide information on basic national indicators of social progress including fertility, childhood mortality, contraceptive knowledge and use, maternal and child health, nutritional status of mothers and children, awareness of AIDS, and domestic violence. Stratified Multi-stage Cluster Sampling design is used to collect data and BDHS-2007 includes 10,996 women of child bearing age of all six divisions in the country and detailed birth histories of 30,474 births [17]. The last birth from the last three years prior to BDHS-2007 survey has been considered for this study.

Factor analysis is used in this study to observe the significant determinant of age at first birth of Bangladeshi women. The main objective is to determine the most significant factors from a set of possible explanatory variables, where factors are non-correlated with each other. Suppose we have a set of p observable random variables $x_{1}, x_{2}, \ldots \ldots \ldots x_{p}$, with means $\mu_{1}, \mu_{2}, \ldots \ldots \ldots \mu_{p}$. Then, for some unknown constants $l_{i j}$ and $k$ unobserved random variables $F_{j}$, and where $k<p$, we have

$$
x_{i}-\mu_{i}=l_{i 1} F_{1}+\ldots \ldots \ldots+l_{i k} F_{k}+\varepsilon_{i}
$$

In matrix notation,

$$
X-\mu=L F+\varepsilon
$$

If we have $n$ observations, then we will have the dimensions $x_{p x k}, L_{p x k}$ and $F_{k x n}$. Each column of $X$ and $F$ denote values for one particular observation, and matrix $L$ does not vary across observations. Any solution of the above set of equations following the constraints for $F$ is defined as the factors, and $L$ as the loading matrix.

Principal Component Analysis was used for extraction of factors and orthogonal rotation (varimax option) to derive non-correlated factors [20]. This varimax method attempts to minimize the number of indicators that have high loading on one factor [21]. Kaiser criterion, namely Eigen value of $>1.0$; is used for the choice of the number of factors in factor analysis. It was also based on the Eigen plot (scree plot), which shows the total variance associated with each other. Scree plot shows the significant factor according to the obtained result based on Kaiser Criterion. Factor loadings greater than 0.5 and cross-loading (loadings with negative value) less than -0.4 are taken into account [22]. The explanatory variables of the current study are selected on the basis of previous literature. Total 13 variables have been taken into account in this study; including respondent's age, marital age, educational level, participation to labor forces, and attitude toward family planning. Few socio-economical variables are also included like gander preference, place of residence (regional and urban/rural), and wealth index and so on.

Hence, Discriminant function analysis was carried out using the factor scores derived through the factor analysis to determine as to how correctly mothers having different age first births are classified. Linear discriminant analysis is used in this study as mothers are classified into two age groups to avoid computational hazards and having precise view of adolescents' fertility scenario.

\section{Results}

Both socio-demographic and proximate covariates are possible determinant of fertility pattern. Obviously, the strength and direction of all covariates for fertility regulation will not be same. In this context, our first step is to search for significant factor and the second step is to find the direction of covariates from that dominant factor. To extract the significant underlying factors behind age at first birth, we use factor analysis based on principal 
components and next, to check the validity of our findings we are conducting discriminant analysis; i.e., which proportion of the observations are correctly classified according to our factor analysis. The adequacy of data was evaluated based on the value of KMO and (homogeneity of variance). The KMO measure compares the value of partial correlation coefficients against the total correlation coefficients. The maximum value of this measure is 1 , and the larger value indicates that most partial correlations are small compared to the total correlations. The parallel line to horizontal at Eigen value equaling to one in scree plot in Figure 1 showed that the five factors will be extracted for age at first birth for BDHS-2007 (see Figure 1).

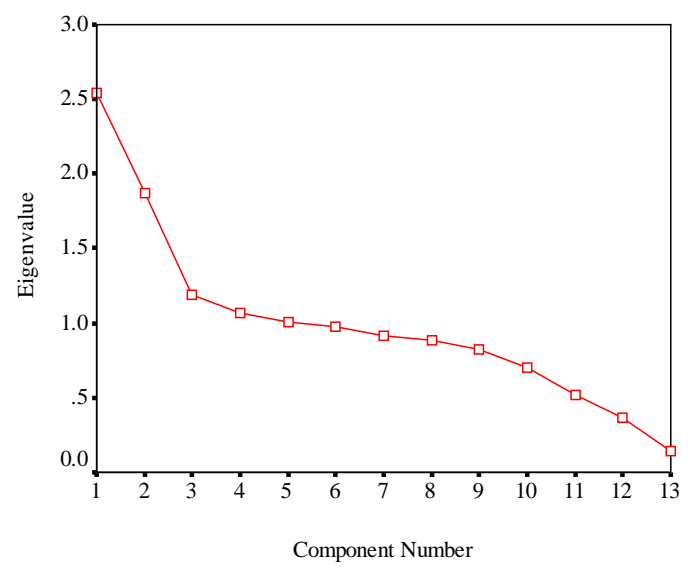

Figure 1. Scree Plot presenting factors behind age at first birth of Bangladeshi women (BDHS-2007)

Table 1. Rotated Component Matrix for age at first birth of Bangladeshi women (BDHS-2007)

\begin{tabular}{|c|c|c|c|c|c|}
\hline \multirow{2}{*}{ Variables } & \multicolumn{5}{|c|}{ Component } \\
\hline & 1 & 2 & 3 & 4 & 5 \\
\hline $\begin{array}{l}\text { Age 5-year } \\
\text { groups }\end{array}$ & -0.003 & 0.942 & -0.019 & 0.011 & 0.005 \\
\hline Division & -0.094 & 0.041 & 0.374 & 0.638 & 0.208 \\
\hline $\begin{array}{l}\text { Type of place } \\
\text { of residence } \\
\text { (Urban/rural) }\end{array}$ & -0.621 & -0.135 & -0.025 & 0.174 & 0.057 \\
\hline $\begin{array}{c}\text { Highest } \\
\text { educational } \\
\text { level }\end{array}$ & 0.635 & -0.418 & -0.062 & 0.113 & -0.005 \\
\hline Religion & 0.027 & -0.011 & -0.047 & -0.062 & 0.505 \\
\hline Wealth index & 0.834 & 0.103 & -0.110 & -0.006 & -0.034 \\
\hline $\begin{array}{l}\text { Contraception } \\
\text { status }\end{array}$ & 0.225 & -0.069 & 0.621 & -0.258 & -0.224 \\
\hline $\begin{array}{c}\text { Age of } \\
\text { respondent's at } \\
\text { first marriage } \\
\text { (grouped) }\end{array}$ & 0.481 & -0.115 & -0.134 & 0.222 & 0.117 \\
\hline $\begin{array}{c}\text { Gender } \\
\text { preference }\end{array}$ & -0.107 & 0.028 & 0.181 & -0.689 & 0.239 \\
\hline $\begin{array}{c}\text { Mass media } \\
\text { exposure }\end{array}$ & 0.746 & -0.082 & 0.110 & -0.005 & -0.015 \\
\hline $\begin{array}{c}\text { Partner's } \\
\text { occupation }\end{array}$ & -0.048 & -0.081 & 0.459 & 0.037 & -0.064 \\
\hline $\begin{array}{c}\text { Respondent's } \\
\text { occupation }\end{array}$ & -0.131 & 0.122 & 0.620 & 0.088 & 0.612 \\
\hline $\begin{array}{l}\text { Husband's age } \\
\text { (grouped) }\end{array}$ & -0.037 & 0.940 & -0.056 & -0.002 & -0.005 \\
\hline
\end{tabular}

Extraction Method: Principal Component Analysis.

Rotation Method: Varimax with Kaiser Normalization.

Rotation converged in 8 iterations.

In the present study, five components were extracted by factor analysis using PCA with varimax rotation for age at first birth. As the factors are obtained from several types of socio-economical, biological and birth history variables, the obtained factors are quite theoretical in nature rather than practical to name. Obtained five factors account for about $59 \%$ of the observed variation in the possible socioeconomical/health/biological variables determining age at first birth of Bangladeshi women (see Table 2).

Rotated component matrix for factor analysis is presented in the following table (Table 1). Here components are the significant components obtained from PCA, and the factors are named later according to the value of loadings and cross-loadings described in the previous section.

Many of the previous research showed significant effect of education and mass media exposure on fertility [12]. Similar findings can be seen in the current study, the first factor is highly correlated with educational level of mother, wealth index and mother's exposure level to mass media. In this context this factor can be named as consciousness factor, as age at first birth increase monotonically with the increase of awareness. Again another reason behind such naming is this factor is negatively related with place of residence (urban/rural), which also indicates the differential status of consciousness on family building dynamics. It should be mentioned that, rural mother have earlier first birth compared to their urban counterpart. According to previous studies, lack of education and participation to labor force are the main reason behind this [14].

The second factor (fecundity factor) has high factor loadings with parent's age, which indicates the fecundity factor; lower aged mothers are normally less fecund than their aged counterpart. This factor is highly correlated with father's age, too. Family planning affects the fertility through use of contraception. Family planning turned to be the third explored factor for age at first birth; due to high correlation with contraception status. High factor loading for mother's employment status can be seen for this factor, which signifies the premises for working mother to have child lately. Although negligible for factor analysis but, notable amount of correlation can be seen for father's occupation. Similar findings were described by previous researchers [15].

In Bangladesh, the socio-economical structure play significant role on fertility. Due to old mentality and socio-economical belief, gender preference is still present. Few studies on gender preference suggest that, fertility level rise in specific region and rural areas due to parent's desire for son rather than daughter [23]. Fourth factor shows high cross loading with gender preference (based on parents prior to birth willingness about gender of upcoming child). These sorts of traditional beliefs/view still play important role on fertility and division plays as a significant differential on these contexts. From the values of factor loadings and cross loading it is difficult to name this factor; we may name this factor as social effect factor. Regional difference in first parity was described in many studies; especially few papers discussed the reason of family planning practice in urban areas. Though the effect of wealth index is few previous study revealed higher level of contraceptive use among slum dwellers in Bangladesh [24].

And the last factor has significant factor loadings with religion and mother's occupation status. It's an established 
fact that working mother want less number of child and it's an important determinant of fertility, too. It's difficult to explain the role of religion on fertility directly but it may be considered as a differential of fertility. Several studies showed that birth intervals are not same for mothers of all religion [25]. Also, due to religious belief many families do not permit women to work outside of home. That's why we are giving priority to employment status and marking this factor as employment factor.

From 13 explanatory variables (components), above explained factors are the significant factors with Eigenvalue more than 1 . These five factors extracted from factor analysis, explain the variation of age at first birth of Bangladeshi women by 19.552, 14.426, 9.174, 8.189 and 7.768 percentages respectively and in total 59.11 percentages of total variation can be explained by these five factors. Table 2 incorporates eigenvalues, percentage of variation explained by each eigenvalue and the cumulative percentage of variation explained by those eigenvalues.

Significant factors obtained from factor analysis (having eigenvalue more than 1) are showed in the following table (Table 2).

Table 2. Total Variance Explained by the obtained factors of age at first birth of Bangladeshi women (BDHS-2007)
\begin{tabular}{|c|c|c|c|c|c|c|c|c|c|}
\hline \multirow{2}{*}{ Component } & \multicolumn{3}{|c|}{ Initial Eigenvalues } & \multicolumn{2}{c|}{ Extraction Sums of Squared Loadings } & \multicolumn{3}{|c|}{ Rotation Sums of Squared Loadings } \\
\cline { 2 - 10 } & Total & $\begin{array}{c}\text { \% of } \\
\text { Variance }\end{array}$ & Cumulative \% & Total & $\begin{array}{c}\text { \% of } \\
\text { Variance }\end{array}$ & Cumulative \% & Total & $\begin{array}{c}\text { \% of } \\
\text { Variance }\end{array}$ & Cumulative \% \\
\hline 1 & 2.542 & 19.552 & 19.552 & 2.542 & 19.552 & 19.552 & 2.365 & 18.191 & 18.191 \\
2 & 1.875 & 14.426 & 33.978 & 1.875 & 14.426 & 33.978 & 2.023 & 15.562 & 33.753 \\
3 & 1.193 & 9.174 & 43.153 & 1.193 & 9.174 & 43.153 & 1.206 & 9.273 & 43.026 \\
4 & 1.065 & 8.189 & 51.341 & 1.065 & 8.189 & 51.341 & 1.054 & 8.111 & 51.137 \\
5 & 1.010 & 7.768 & 59.109 & 1.010 & 7.768 & 59.109 & 1.036 & 7.972 & 59.109 \\
\hline
\end{tabular}

Extraction Method: Principal Component Analysis

Discriminant function analysis was used for studying the relationship between the explored factors in factor analysis and mother's age at first birth, presented in Table 3 . The factor scores obtained by the factor analysis for age at first birth were considered continuous independent variables, and age at first birth of the individuals was considered dichotomous dependent variable. Mothers entered into child bearing state in early age (below 20) and others (above 20) are considered as two groups for this analysis. The reason behind such groupings is to know the efficiency of our findings for adolescent mothers precisely and to avoid computational complexity (see Table 3).

Table 3. Classification of individual mothers using scores derived from factor analysis for age at first birth of Bangladeshi women (BDHS-2007)

\begin{tabular}{|c|c|c|c|c|c|}
\hline \multirow{2}{*}{\multicolumn{3}{|c|}{ Age at first birth (dichotomous) }} & \multicolumn{2}{|c|}{$\begin{array}{l}\text { Predicted Group } \\
\text { Membership }\end{array}$} & \multirow[t]{2}{*}{ Total } \\
\hline & & & $<20$ & $\geq 20$ & \\
\hline \multirow{4}{*}{ Original } & \multirow{2}{*}{ Count } & $<20$ & 5585 & 2181 & 7766 \\
\hline & & $\geq 21$ & 494 & 921 & 1416 \\
\hline & \multirow[t]{2}{*}{$\%$} & $<20$ & 71.9 & 28.1 & 100.0 \\
\hline & & $\geq 20$ & 34.9 & 65.1 & 100.0 \\
\hline
\end{tabular}

$70.9 \%$ of original grouped cases correctly classified

The distributions of mother's age at first birth by the discriminant function analysis using the factor scores obtained from factor analysis are presented in Table 3. Based on the discriminant function analysis, overall $70.9 \%$ of the mother's age at first birth was predicted correctly. For lower aged and adolescents mothers (below 20), $71.9 \%$ of the mothers were classified correctly; while for other mothers (above 20), 65.1\% observations were correctly classified. In other words, sensitivity of discriminant function was $71.9 \%$ and the specificity was $65.1 \%$.

\section{Discussion}

First birth is a transition marks to a woman into motherhood; is also an important indicator for maternal health. Delaying first births is an important mechanism that contributes to decreasing the quantum of fertility; when all other factors being equal, couples who conceive first births earlier may be more fecund than couples who conceive later, and that will show up in completed fertility. Overall, fertility depends not only on the decisions of couples but also on many socioeconomic, demographic, health related as well as tradition-related and sometimes on emotional factors. In current study, multivariate techniques are used to explore the underlying factors that determine the respondent's age at first birth using the data of BDHS-2007. Obtained results suggest, consciousness factor, fecundity factor, family planning factor, social effect factor and employment factor are the significant determinant of age at first birth of Bangladeshi women. Adequacy of the findings was verified by discriminant analysis which suggests 70.1 percent of the total observations were correctly classified according to the factor scores obtained from the factor analysis.

Almost all of the previous studies marked lack of consciousness as the key determinant of fertility boost, along with public health related issues $[3,18]$. Same result is obtained in current study. According to factor analysis, highest amount of variation is explained by consciousness factor. It's proved that, educated mother always seek for less number of child and have awareness about benefit of delayed childbearing. But in socio-economic context of Bangladesh, women's education level still depends on family structure/socio-economical condition due to religious and other social view [19]. Without improvement in women's education scenario rapid improvement in fertility scenario is not possible. Again it is also related to mother's participation to labor force. Mother's employment status shows significant impact on age at first birth. It also have some relation with education level of mothers, if educated mothers don't have appropriate job they will not be interested to get higher educated. So, government also need to suitable job market for them, which is still tough one for a developing country like Bangladesh. It is notable that recent BDHS reports suggest improve in scenario of women's education level and working status [17]. 
Fecundity came as the second highest variation explaining factor in factor analysis. Effect of contraception status was also present in this factor. It should be noted that contraception is the key factor to family planning, so the main criterion is the couple's decision to move to the next parity. Recent BDHS report, previous studies showed significant increase in use of contraception prevalence [19]. To have maximum gain, family building norm and benefit of lengthier entrance to parity hood needed to be mentioned to the couples. Steps should be taken to improve the spousal communication about family planning, promote small family norms and optimum spacing between pregnancies. Additional attention should be given to newlywed couples and implementing reproduces health programs among the adolescents. Overall, increasing awareness level by counseling through social activities would be a good way to restrain mothers from early childbearing.

Like previous studies, our results also indicate rural mothers have their first child earlier compare to their urban counterparts. Mass media campaign was sophisticated to reduce fertility level in the recent decades, now it is needed to again to raise awareness about Risk of early age pregnancy especially in the rural areas to improve current situation. Age at marriage, age at first birth and marital duration are highly correlated for number of parity [6]. Recent reports indicate the decline in earlier marriage in rural areas, but still not in a remarkable pattern. Few socio-cultural views are difficult to change; education and mass media can improve these scenarios. From our findings we can suggest women to marry at later age. Or, government can take necessary steps to resist women to marry before a certain age, say 20 years.

The power of mass media is vast; it can be used prominently to make rapid change in any socio-cultural or socio-economical issues. We can use mass media to raise consciousness among general people about the benefit of lower fertility and risk of early entrance of mothers to child bearing state.

\section{Acknowledgement}

An earlier version of this paper was presented in Seventeenth Mathematics Conference, Jahangirnagar University (22-24 Dec, 2011), Dhaka, Bangladesh.

\section{Competing interests}

The authors declare no conflict of interest.

\section{References}

[1] Mathews, T.J. and Hamilton, B.E., Delayed childbearing: More women are having their first child later in life, NCHS data brief, National Center for Health Statistics, Hyattsville, MD, 2009, Aug, (21). 1-8.

[2] Coombs, L.C., and Freedman, R., "Premarital Pregnancy, Childspacing, and later Economic Achievement”, Population Studies, 24. 389-412. 1970.

[3] LeGrand, T.K. and Mback'e, C.S.M., "Teenage pregnancy and child health in the urban Sahel”, Studies in Family Planning, 24 (3). 137-149. 1993.
[4] Westoff, C.F., Age at marriage, age at first birth and fertility in Africa, World Bank Technical Paper no. 169, The World Bank, Washington D.C. 1992.

[5] Zabin, L. and Kiragu, K., "The health consequences of adolescent sexual and fertility behavior in sub-Saharan Africa”, Studies in Family Planning, 29 (2). 210-232. 1998.

[6] Hobcraft, J., "Fertility patterns and child survival: a comparative analysis”, Population Bulletin, United Nations, NY, 33. 1-31. 1992.

[7] Roudi-Fahimi, F., "Iran's family planning program: Responding to a nation's needs", MENA policy brief, Population Reference Bureau, Washington, DC. 21. 2002.

[8] Abbasi-Shavazi, M.J., Mehryar, A.H., Jones, G., and McDonald, P., "Revolution, war and modernization: Population policy and fertility change in Iran”, Journal of Population Research, 19 (1). 25-46. 2002.

[9] Erfani, A. and Mcquillan, K., "Rapid fertility decline in iran: Analysis of intermediate variables", Journal of Biosocial Science, 40 (3). 459-478. 2008.

[10] Stephen, O.G., "A Cohort Analysis of the Timing of First Birth and Fertility in Ghana", Population Research and Policy Review, 22. 251-266. 2003.

[11] Hashemi, A. and Salehi-Isfahani, D., "Family Planning Program Effects in Rural Iran", The Northwest Universities Development Consortium (NEUDC) Conference, Tufts University, Melford, M.A. 2009.

[12] Lappegård, T. and Rønsen, M., "The Multifaceted Impact of Education on Entry into Motherhood”, European Journal of Population, 21. 31-49. 2005.

[13] Kirsten, K.W., "Education, Age at first Marriage or First Birth and Labour Force Participation as Predictors of Parity Transitions: An Application of Discrete Multivariate Analysis to the study of Conditional Life Table Probabilities", Canadian Studies in Population, 14 (1). 89-109. 1987.

[14] Ngalinda, I., "Age at First Birth, Fertility, and Contraception in Tanzania”, Doctoral dissertation, Humboldt University of Berlin, Germany. 1998.

[15] Teachman, J.D. and Schollaert, P.T., "Economic Conditions, Marital Status, and the Timing of First Births: Result for Whites and Blacks", Sociological Forum, 4 (1). 27-46. 1989.

[16] Rindfuss, R. and John C.R., "Social Determinants of Age at First Birth”, Journal of Marriage and Family, 45 (3). 553-565. 1983.

[17] National Institute of Population Research and Training (NIPORT), Mitra and Associates, and Macro International, Bangladesh Demographic and Health Survey 2007, Dhaka, Bangladesh and Calverton, Maryland, USA: National Institute of Population Research and Training, Mitra and Associates, and Macro International. 2009.

[18] Haque, M.A. and Sayem A.M., "Socioeconomic Determinants of Age at First Birth in Rural Areas of Bangladesh", Asia Pacific Journal of Public Health, 21 (1). 104-111. 2009.

[19] Abedin, S., "Identification of Fertility Enhancing and Inhibiting Factors: A Study on Married Adolescents in Bangladesh”, Asian Social Science, 7 (5). 191-196. 2011.

[20] Hair, J.F., Anderson, R.E., Tatham, R.L., and Black, W.C., Multivariate Data Analysis with Readings, Prentice-Hall, Englewood Cliffs, New Jersey, 4th ed., 1995.

[21] Mardia, K.V., Kent, J.T., and Bibby, J.M., Multivariate Analysis, Academic press, London, 1980.

[22] Johnson, R.A. and Wichern, D.W., Applied Multivariate Statistical Data Analysis, Prentice Hall, New Jersey, 2002.

[23] Hajian, K., Asnafi, N., and Aliakbarnia-Omran, F., "Birth Intervals and Associated Factors in Multi-Para Women Residing in Babol, Northern Iran”, Journal of Mazandaran University of Medical Sciences, 66 (18). 63-70. 2008.

[24] Mostafa Kamal, S.M., "Contraceptive Use and Method Choice in Urban Slum of Bangladesh". International Conference on Family Planning: Research and Best Practices, Kampala, Uganda, 15-18 November, 2009.

[25] Bavel, J.V. and Kok, J., "Birth Spacing in the Netherlands: The Effects of Family Composition, Occupation and Religion on Birth Intervals 1820-1885", European Journal of Population, 20 (2). 119-140. 2004. 